RESEARCH PAPER

\title{
Feasibility of implementing intervention methods in an adolescent worksite tobacco control study
}

\author{
M K Hunt, P Fagan, R Lederman, A Stoddard, L Frazier, K Girod, G Sorensen
}

Tobacco Control 2003;12(Suppl IV):iv40-iv45

See end of article for authors' affiliations

.....................

Correspondence to: Mary Kay Hunt, MPH, RD, Dana-Farber Cancer Institute, 44 Binney Street, Room SM256, Boston MÁ 02115,USA; mkhunt@ cox.net

\begin{abstract}
Objective: To present feasibility data on SMART, the first teen worksite behavioural tobacco control intervention.

Design: This phase II study was designed to estimate the efficacy and feasibility of a small scale, randomised, controlled intervention.

Setting and subjects: This study, addressing youths aged 15-18 years, was implemented in four intervention and five control grocery stores that had an average of 44 eligible teens.

Interventions: The tobacco use cessation and prevention interventions were based on social influences and peer leader models. Employee break rooms served as centres both for interactive activities including open houses, teen advisory boards, peer leader interviews, games and contests; and non-interactive interventions including bulletin boards and table tents with health messages and home mailings.

Main process measures: Project staff collected process data on the extent of implementation of intervention activities, participation rates in activities, and contacts with peer leaders. On the final survey, teens reported on awareness of, participation in, and motivation for participating in project activities.

Results: Indicators of feasibility were identified and discussed, including the number of activities implemented, teen participation, management support, cost, and barriers to and facilitators of implementation. During the 12 month intervention, a mean of 24.1 interactive activities and 55.3 noninteractive activities were implemented, and a mean $14.2 \%$ participation rate per activity per site was achieved. Eighty four per cent of teens reported being aware of SMART, and 39\% reported participating in interactive and $67 \%$ in non-interactive activities.

Conclusions: Teen smoking cessation rates in worksite programmes might be improved if they are conducted in companies where there is job stability and if teen programmes are part of worksite-wide tobacco control programmes that include both teens and adults.
\end{abstract}

$\mathrm{n}$ response to the evidence that most adults begin smoking in their teen years, ${ }^{12}$ schools and communities have been used as channels for tobacco prevention and control programmes for teens. ${ }^{3-6}$ Researchers have suggested, however, that for some adolescents school health education alone may not be effective ${ }^{7}$ and recommend that school programmes be seen only as part of a broader programme in tobacco control for adolescents. ${ }^{2} 8$

National studies indicate that $80 \%$ of teens work at some point during high school. ${ }^{9-11}$ There is evidence that employment and working long hours are associated with increased risk of smoking among adolescents. ${ }^{12-14}$ Thus, worksites that employ teens might serve as additional intervention channels in comprehensive adolescent tobacco control programmes. To our knowledge, no programme to date has implemented behaviour change programmes for teens in the workplace. Therefore, we planned SMART Teens Against the Risk of Tobacco as a phase II methods development study in order to design and test innovative interventions ${ }^{15}$ before launching a full scale trial. In SMART we tested the efficacy and feasibility of an intervention targeting smoking prevention and cessation among youth employed in the grocery store setting. As specified by Greenwald and Cullen ${ }^{15}$ and Flay, ${ }^{16}$ phase II studies provide an important step in the development of new approaches to health promotion, including conducting exploratory research, hypothesis development, and pilot testing or preliminary tests of new approaches.

The results of this study indicate that smoking prevalence decreased and intention to quit increased more among teens in the intervention stores than in the control stores, but the differences were not significant. ${ }^{17}$
We used process evaluation as a tool for documenting indicators of feasibility such as teen participation, management participation, barriers, facilitators, and costs of implementation. Systematic process evaluation enables investigators to determine the characteristics of intervention methods that make programme effectiveness results more interpretable, ${ }^{18}$ explain variability in results, ${ }^{19}$ and inform future studies. ${ }^{18}{ }^{19}$ Effective process evaluation systems reflect the theoretical model upon which the interventions are based, ${ }^{18}{ }^{19}$ use multiple data collection methods, and incorporate perspectives of various groups involved in the study ${ }^{19} 20$ including the amount of intervention implemented by programme staff and the amount received by programme participants. $^{21}$ The SMART process evaluation system was designed based on these principles.

The purposes of this paper are to:

- describe SMART intervention planning and implementation methods

- report process evaluation data related to the extent of implementation and reach of the intervention

- identify and discuss indicators of feasibility

- make recommendations for future studies.

\section{METHODS}

\section{Study design}

The phase II (methods development) randomised, controlled SMART study was designed to assess the feasibility and estimate the efficacy of a worksite tobacco prevention and cessation intervention for youth aged 15-18 years. Details of 
programme evaluation and efficacy are reported elsewhere. ${ }^{17} 22$

\section{Study setting and participants}

This intervention study was based in nine grocery stores that were part of a single supermarket corporation. To be eligible for the study, stores were required to employ at least 40 teens and be located within a 45 mile radius of Boston, Massachusetts. Along with corporate upper management representatives we identified 12 of 52 grocery stores that met these inclusion criteria. These 12 stores were then randomly assigned to intervention and control sites. Of these, three stores were dropped from the study because of excessive turnover of teen employees (two stores) and store closing (one store). The 12 month intervention was implemented in four stores, and five stores served as control sites. All stores were smokefree and smokers smoked on their scheduled breaks in an outdoor area.

\section{Intervention methods}

Smoking cessation was the primary aim of this study because the audience included older teens for whom quitting was especially relevant. Many cessation messages, however, also are appropriate for prevention. In initiating the first worksite tobacco control programme for teens, we addressed prevention as well as cessation. The intervention framework incorporated theories based on a social influences model ${ }^{23-25}$ and used peer led methods of intervention delivery. ${ }^{26-28}$ The rationale for using peer leader implementation models was derived from the social influences theory ${ }^{26}$ and often is used in school health programmes. ${ }^{29-31}$ In this case we recruited teens from among those employed in the individual stores to work with DFCI staff to plan and implement interventions. We used the planning process suggested by Perry $e a^{30}$ to: (1) identify factors predictive of teen smoking, (2) formulate intervention objectives that described how the intervention would change the predictive factors, and (3) plan intervention activities that have been shown to be associated with behaviour change in teens, would attract teens to participate, and were feasible in the grocery store environment. We identified three categories of factors that predict teen tobacco use: (1) social/environmental factors (social norms, role models, social support, barriers and opportunities for quitting); (2) personal factors (beliefs about the health and social consequences of smoking, knowledge of nicotine addiction, awareness of resources for quitting, functional meaning of smoking, self efficacy for quitting, and self esteem); (3) behavioural factors (behavioural intentions, skills to refuse to take up smoking or quit smoking, communication, goal setting, and stress management); and (4) life skills (communication, decision making, goal setting, stress management, job skills). Our intervention plan included 37 specific behavioural objectives that we addressed in the design of intervention activities. ${ }^{30}$ Over the one year intervention period, we monitored the implementation of interventions addressing these objectives on a monthly basis. On average, each month our intervention activities addressed social/ environmental factors 5.6 times, personal factors 10.75 times, behavioural factors twice, and life skills 3.6 times.

For example, in the category of personal factors, one of our objectives was to "increase the percentage of teens who identify and choose healthful activities instead of smoking to relieve boredom, help me relax, reduce stress, frustration and tension, control weight, get more respect from peers and have more friends and dates". One method we used to address this objective was the placement of "teen friendly" messages on bulletin boards and in table tents. For the theme of horoscopes, one message read, "Mars in the $7^{\text {th }}$ house spells $S * T * R^{*} E^{*} S * S$ for Sagittarians. Instead of smoking try getting that "archer" body on the dance floor or soccer field to relieve stress, or talk it out with a low-key Libra."

Although interactive activities are associated with a greater likelihood of behaviour change, we also provided noninteractive intervention opportunities that could be in place during hours when the stores were open and project staff and peer leaders were not available.

\section{Interactive activities}

We developed open house events, teen advisory boards, teen interviews, and games and contests that involved personal interaction of employed teens with peer leaders, project staff, and with each other. We repeated a cycle of interactive interventions approximately every three months to provide an opportunity for exposure to the intervention for new hires. We implemented approximately two interventions each month. Open house events featured contests, games, demonstrations, and testing of expired air with a carbon monoxide analyser. Teen advisory boards provided an interactive channel for life skill and tobacco control education as well as a venue for obtaining teens' continuous input into intervention development. We trained peer leaders and teen advisory board members to interview their peers about subjects related to project intervention objectives and adapted games and contests from popular board games, game shows, and web sites. We provided incentives such as food and items such as hats, CD holders, and key chains with the programme name and logo to raise awareness of the programme and to attract teens to activities.

\section{Non-interactive interventions}

In the break rooms, we used non-interactive intervention strategies to which teens had access during times when peer leaders and project staff were not in the store. To create a project identity and provide a central location for the distribution of educational materials and implementation of activities, we established a SMART Center in store break rooms. SMART Centers consisted of bulletin boards with wall pockets and table tents that we used to display teen relevant educational messages. The bulletin boards were changed about once a month and messages on table tents about every two weeks. Bulletin board displays included posters replicating teen magazines with pictures of popular non-smoking teen movie stars and recording artists. On table tents, we displayed results of interviews with teen employees about their experiences with tobacco and used a series of "weird facts" and "brain teasers" to convey smoking cessation and prevention messages. Our advisors told us that teens enjoy receiving mailings at home, so we prepared postcards with project messages and mailed them to teens' homes. For example, on the front of one mailing we reproduced a recent tobacco industry ad and on the back displayed a checklist of ways to "deconstruct" the images in the ad. Those who completed the checklist and returned the postcard were eligible for a prize.

Peer leader implementation of intervention activities Before the beginning of the intervention, we identified one to two peer leaders for each intervention store and provided a series of four formal group interactive peer leader training sessions titled: Roles and responsibilities of peer leaders; Teens, smoking, and addiction; Effective communication skills; and Engaging in informal conversations. An additional three continuing education sessions were held during the latter half of the intervention. These trainings focused on how to hold an open house event, how to co-facilitate a teen advisory board meeting, and how to conduct peer-to-peer interviews. Condensed trainings of all seven sessions were held for teens who became peer leaders during the course of 
the intervention. Project staff also provided ongoing support for the peer leaders through face-to-face contacts, email, telephone, and mail. Staff provided a mean of 40.5 contacts per peer leader. The peer leaders served as communication links between teens and project staff; helped organise, plan, and promote interventions; served as a resource for teens for cessation and tobacco related educational materials; and delivered project messages at SMART activities or on a oneto-one basis. After about two months of intervention implementation we determined that the peer leader model in the grocery store setting needed modification so we recruited additional teens to serve with peer leaders on advisory boards of four to seven members in the intervention stores.

\section{Data collection and measures}

We used two sources for the collection of process data: (1) a quantitative process evaluation system ${ }^{32}$ that was used to collect data from the perspective of programme implementers; and (2) the final survey ${ }^{33}$ of the SMART participants that collected data from the perspective of the recipients of the intervention.

\section{Process evaluation system}

Research staff recorded the type and number of activities offered and the number of teens who participated in each activity on an intervention tracking form (ITF). The ITF included spaces for the title, date and duration of the activity, the number of participants, intervention type, educational components, and the emphasis of each intervention (smoking prevention, smoking cessation, life skills, and media influences). For interactive activities, staff documented appropriate fields on the ITF and recorded the number of teens who participated. To obtain the mean number of minutes of exposure per site, we multiplied the number of people who attended each activity by the average number of minutes participants attended. For example, teens were allowed to attend open houses on their 15 minute breaks and teen advisory board meetings lasted one hour. We then calculated mean person minutes of intervention exposure for each activity. We then summed mean person minutes for all activities to get a total of teen minutes of exposure per worksite.

For non-interactive activities, staff documented the times there were changes in health messages on the bulletin boards and table tents in the SMART Centers. Project staff also kept a log in which they recorded the type and method of contact with peer leaders each week. Choices for the types of contacts include face-to-face, phone, email, mail, and other.

\section{Final survey}

We included questions on the final survey that asked teens about their awareness of and participation in project activities as well as their motivation for participation. Employed teens between the ages of 15-18 years were eligible to participate in the intervention. The survey was self administered, either in groups, or was distributed to and collected from individual teens when they were unable to participate in group administration. A total of 252 (72\% of those eligible) teens responded to the final survey over the two month administration period. Study protocol was approved by the Institutional Review Board (IRB) of DanaFarber Cancer Institute. Additional details on final survey administration are reported in the SMART companion article in this issue. ${ }^{33}$

The programme awareness question asked: "Over the past year, have you heard of any of the following programmes that have been offered in your store?" Names of four possible programmes, including SMART, were given, and only "yes" responses to the SMART choice were scored as correct.

To measure the amount of intervention received by teens, we asked teens to respond to the question: "Over the past year, have you done any of the following activities [related to teens and smoking] at your store? (Please circle all that apply.)" Seven possible responses included reading posters or table tents, reading a bulletin board, participating in games or contests, participating in group discussions, and talked to a teen co-worker. "Yes" responses on any item were considered participation. We collapsed the responses to "reading posters, table tents and a bulletin board" into a non-interactive category and included the remaining responses into an active intervention category.

To examine motivators for attendance we asked: "How much did each of the following motivate you to attend a SMART activity/event?" Possible responses included money, food, prizes, meeting with friends, the event sounded interesting, time off work and other. Four response categories ranged from "not at all" to "a great deal".

\section{Data analysis}

Results for each assessment (process evaluation and final survey) were aggregated to the worksite level, and the worksite was the unit of analysis. For process evaluation data, the number of activities and number of participants at every activity at each worksite were used to calculate participation rates per activity. From the final survey data we report mean participation in all activities by worksite.

\section{RESULTS}

\section{Worksite level characteristics}

While most worksite level characteristics of teens in intervention and control stores were similar, there were higher percentages of teens who had ever smoked and were current smokers in the intervention stores (table 1).

\section{Results from process evaluation}

In table 2 we describe the amount of intervention delivered to teens. Programme staff provided a mean of 24.1 interactive and 55.3 non-interactive activities per site, and documented a mean participation rate of $14.2 \%$ per interactive activity, ranging from $1.9 \%$ for teen interviews to $28.4 \%$ for open houses. The mean interactive intervention exposure rate was 113 minutes per teen per site.

\section{Results from the final survey}

On the final survey, $84 \%$ of teens in intervention stores correctly recognised SMART as the project name. A mean of $39 \%$ of teens reported participating in interactive activities and $67 \%$ in non-interactive interventions. Only $13 \%$ of teens reported participating in none of the activities (table 3 ). The figures for control stores provide an indicator of the level of social desirability responses to these questions, although teens in control stores may have been exposed to educational materials such as posters and bulletin boards provided by non-SMART sources. Money and prizes were ranked highly by both intervention and control groups as motivators. Participants in the intervention sites were asked to select motivators that they had actually experienced during the course of the intervention while participants in control stores responded to a hypothetical situation.

Most intervention activities incorporated multiple educational components such as self assessments, displays with and without personal interaction, demonstrations, and games and contests. Staff documented the emphasis of each component and we calculated a mean number of educational components delivered per site. Although not displayed on a table, we documented a mean number of 138 smoking 
Table 1 Worksite level characteristics of employed teens by condition

\begin{tabular}{lll}
\hline & \multicolumn{2}{l}{ Final survey } \\
\cline { 2 - 3 } Worksite level characteristics & Intervention & Control \\
\hline Mean age (in years) & 16.5 & 16.3 \\
Mean \% male & 52 & 56 \\
Mean \% white, non-Hispanic & 64 & 58 \\
Mean \% who have ever smoked & 25 & 18 \\
Current \% smoker & 30 & 21 \\
$\%$ attend school & 93 & 94 \\
Mean tenure at job (in months) & 19 & 16 \\
Hours worked per week: & 33 & 40 \\
$\% \geqslant 20$ in school year & 30 & 32 \\
$\%<20$ during school year, $\geqslant 20$ in summer & 30 & 29 \\
$\%<20$ during school year or summer & 37 & \\
\hline
\end{tabular}

cessation components, 124 smoking prevention components, 50 life skills components such as healthful ways to deal with stress, communication and body image, and 13 addressing media influences.

\section{DISCUSSION}

In this paper we discuss the feasibility of implementing a teen behaviour change programme in a grocery store environment as reflected in feasibility indicators including the number of activities implemented, teen participation rates, management support for intervention implementation, cost, and barriers to and facilitators of implementation.

\section{Number of activities and teen participation rates}

We implemented a mean of 24.1 activities in the four intervention stores and a mean of $14.2 \%$ of eligible teens participated in each activity (range 1.9-28.4\%). Thirty nine per cent of teens reported that they participated in interactive activities and over two thirds reported exposure to noninteractive interventions. With these levels of intervention implementation and participation, we observed higher levels of smoking cessation and greater levels of intention to quit in the next 30 days in the intervention than in the control stores. These results, however, were not significant.

\section{Management support}

Management support is crucial to effective worksite health promotion programming. ${ }^{34}$ At the beginning of the SMART project there was strong upper management support. We had worked with upper management on a project to provide nutrition education through their stores and had built a trusting, collaborative relationship. The corporation's mission statement included service to the community and this project was one way of carrying out their mission. A collaboration with a well known and respected cancer research centre in their community provided a public relations advantage. However, the store was bought out during the course of the intervention and thus we had to start over building trust with a new organisational structure and upper management personnel.

The work environment at the level of the grocery stores is fast paced and support from local store managers varied. In community based research, problems can arise from differing priorities of the collaborators. While management's top priority is the production of business goods and services, health researchers' top priority is study design and employee health. There are opportunities both for accommodation and conflict between priorities. To build on shared values of the importance of cancer prevention, we acknowledged the store's collaboration in project publicity and on all educational and promotional materials. An example of a conflict in priorities was the fact that the stores actually sold tobacco products and cigarettes. We dealt with this issue by providing the no-smoking messages of intervention activities in break rooms to which shoppers did not have access.

\section{Costs}

Project staff encouraged managers to schedule teens' break times to coincide with intervention activities and the project provided stores with financial reimbursement for the time teens attended project activities on work time. In recognition of the fact that focusing on the long term health outcomes of tobacco use would not likely attract teens to project activities, ${ }^{36}$ we used a variety of extrinsic incentives including food and prizes. Also, we appealed to social influences such as relationships with peers and appearance as motivators for participation. The costs of the reimbursement for work time and extrinsic incentives reduce the generalisability of this intervention.

\section{Barriers to and facilitators of intervention implementation}

Many of the barriers to programme implementation were related to the structure of the work of part time teens. The high turnover rate and irregular work schedules made it difficult to provide adequate exposure to the intervention. For teens, the mean tenure on the job was 16-19 months. Only a third of teens worked 20 or more hours a week during the

Table 2 Mean (SD) of indicators of amount of intervention (number of activities), reach (participation), and peer leader participation documented by programme implementers with the process evaluation system

\begin{tabular}{|c|c|c|}
\hline Interventions implemented & $\begin{array}{l}\text { Mean }(S D) \\
\text { number/site }(n=4)\end{array}$ & $\begin{array}{l}\% \text { (SD) participation } \\
\text { /activity/site }(\mathrm{n}=4)\end{array}$ \\
\hline \multicolumn{3}{|l|}{ Interactive activities } \\
\hline Open houses & $3.8(1.5)$ & $28.4(14.7)$ \\
\hline Teen advisory boards & $5.7(.58)$ & $9.9(4.8)$ \\
\hline Peer leader interviews & $4.5(.57)$ & $1.9(.47)$ \\
\hline Games and contests & $8.8(2.5)$ & $13.6(4.5)$ \\
\hline Carbon monoxide assessment & $1.3(.58)$ & $17.1(9.3)$ \\
\hline Total & $24.1(1.3)$ & $14.2(10.2)$ \\
\hline \multicolumn{3}{|l|}{ Non-interactive activities } \\
\hline Changes in SMART Center bulletin boards & $11.5(1.0)$ & N/A \\
\hline Changes in messages on table tents & 40.5 (1.9) & N/A \\
\hline Home mailings & 3.3 & N/A \\
\hline Total & 55.3 & N/A \\
\hline $\begin{array}{l}\text { Mean number of minutes of interactive intervention } \\
\text { exposure/site }\end{array}$ & $113(14.4)$ & N/A \\
\hline
\end{tabular}

$\mathrm{N} / \mathrm{A}$, not applicable. It was not possible to document teen contact with non-interactive interventions. 


\begin{tabular}{|c|c|c|}
\hline Variable & $\begin{array}{l}\text { Intervention \% (SD) } \\
(\mathrm{n}=4)\end{array}$ & $\begin{array}{l}\text { Control \%(SD) } \\
(n=5)\end{array}$ \\
\hline Awareness of the SMART project & 84 & 28 \\
\hline \multicolumn{3}{|l|}{ Participation in SMART project activities } \\
\hline Interactive activities & 39 & 8 \\
\hline Non-interactive activities & 67 & 33 \\
\hline None of the specified activities & 13 & 43 \\
\hline Factors motivating to attend SMART activities (from all teens) & Intervention \% (rank) & Intervention \% (rank) \\
\hline Prizes & 66 (1) & 36 (3) \\
\hline Money & $61(2)$ & $43(1)$ \\
\hline Food & 57 (3) & $31(6)$ \\
\hline Time off work & 57 (3) & $34(4)$ \\
\hline Event sounded interesting & $52(4)$ & 39 (2) \\
\hline Meeting with friends & $49(5)$ & $33(5)$ \\
\hline
\end{tabular}

school year (table 1.) We developed several strategies in response to these challenges. Because of the high turnover rates, we planned cycles of interventions so that activities were repeated at approximately three month intervals providing intervention exposure for newly hired teens. To accommodate irregular schedules over the extended period of time that stores were open, we used a combination of interactive and non-interactive interventions in the Smart Center to assure that there were opportunities for exposure to intervention messages in the absence of project staff and peer leaders. We scheduled project staff and peer leaders to implement interactive interventions on weekends when the largest number of teens worked.

In a review comparing peer led and adult led school health education, Mellanby et al concluded that peer leaders were at least as, or more effective than, adults but that because of analytical and methodological problems with the studies reviewed, the case for peer led health education is not clearly established. ${ }^{27}$ Because of the equivocal findings in this review and because the preponderance of teen health programmes in communities and schools do use peer leaders we chose to test this intervention delivery method in a worksite setting. We learned, however, that the peer leader implementation model had limited applicability in this worksite setting for several reasons, including the fact that most teens' close friendship groups that were most likely "to influence the expectations, attitudes and behaviors of the groups to which they belong" ${ }^{\prime 26}$ were with school friends and not co-workers. In addition, the combination of geographically separated intervention stores and teens' lack of access to transportation meant that with only one to two peer leaders in each store, it was difficult to establish group cohesion among the peer leaders that could foster group action. We found that teens, particularly younger teens, were reluctant to engage their peers in "informal conversations" about tobacco use as is evidenced by the low number of peer leader interviews (4.5 per store) implemented. The mean age of peer leaders was 16 years. We learned with our interactions with peer leaders that they were more comfortable as assistants to DFCI staff than in taking the lead role in intervention implementation. We were, however, successful in maintaining contact with peer leaders and learned that most teens had access to email. To increase the number of involved teens, we formed advisory boards of 4-10 teens and this extended the possibilities for project reach.

Because we addressed only one segment of the workforce, we were restricted to providing environmental cues to smoking prevention and cessation only in the break rooms. Thus, we were unable to interact with the entire workforce to build worksite-wide social norms and social support for being smokefree.

There are limitations to the interpretation of the data reported here. Sources of both process evaluation and survey data were self report. Although self report is commonly used in epidemiological research because of its feasibility, it can introduce reporting bias. Barriers to implementation described above may also affect generalisability of study results.

\section{Conclusions}

It is likely that the impact on smoking cessation rates for future teen worksite tobacco control programmes can be improved if they are conducted in companies where there is more job stability among employed teens. These occupations might include summer jobs such as lifeguard work, jobs that are part of a summer job corps programme or school to work programmes in which $40 \%$ of youth participate. ${ }^{37}$ Of the $78 \%$ of employed teens who work in the retail or service sector, $28.3 \%$ are employed in eating and drinking establishments ${ }^{38}$ which might be settings conducive to reaching teens. Also, it may be more efficacious for teens to participate in worksitewide tobacco control programmes that include both teens and adults so that the programmes would be more likely to have an impact on worksite-wide social norms. ${ }^{39}$ Management commitment might be greater for a programme that benefits the total workforce.

We concluded that the traditional peer leader model was not well suited to the grocery store setting. This model may be appropriate in companies that have a common geographic location and where teens are older and are employed fulltime, conditions that would increase the likelihood of cohesive relationships forming in work groups.

\section{ACKNOWLEDGEMENTS}

This study was supported by the National Institute of Nursing Research and the National Cancer Institute, grant number R0l NR04748. The authors are grateful to the investigators and staff who participated on the project, including Jay S Clark, Gina Escamilla, Chris Grasso, Elizabeth Harden, Dana Jessup, Kerry Kokkinogenis, Hye-Seung Lee, Ruth Lederman, Stefania Maggi, Richard Martins, Rachel Noriscat, Anil Pillay, Steve Potter, Lois Rasmussen Norstrom, Prabhjyot Singh, Dana Spain, Evelyn Stein, Rosemary Thom, Travis Trammell, David Wilson, and Kathleen Yaus. The authors would also like to thank the Scientific Advisory Board for their contributions to the development of the assessment tools and other study components, including Drs J Allan Best, Graham A Colditz, William DeJong, Steven L Gortmaker, Nancy Rigotti, and Michael Segal and Ellen Frank, Judy Foley, and Jeanne M Medas. This work would not have been possible without the collaborative efforts of the upper management, store managers, and teen employees of the worksites that participated in this study. 


\section{What this paper adds}

Previous intervention studies of adolescent tobacco control have been conducted in school and community settings. Because $80 \%$ of adolescents work at some time during their high school career, worksites that employ teens might serve as additional channels for adolescent smoking cessation and prevention programmes.

In this first workplace intervention study for teens, we adapted peer leader methods and educational strategies that have been tested in school and community settings. We learned that the high turnover rates and irregular work schedules of teens employed in the grocery store environment reduced the potential for exposure to interventions. We were, however, able to engage teens in intervention planning and implementation and in the 12 month intervention delivered a mean of 24.1 activities per worksite and achieved a $39 \%$ participation rate in interactive interventions and $67 \%$ participation in non-interactive interventions that were in place throughout the hours that stores were open. In addition, we found that the peer leader model had limited applicability in the grocery store setting. Barriers to the peer leader model included the fact that employed teens' primary friendship groups were at school and not at work. Also, the geographic separation of stores limited opportunities to create group cohesion among peer leaders. Because the intervention addressed only one segment of the workforce, we were unable to implement worksite-wide interventions that could have an impact on social norms. Future research with employed teens may need to be conducted in work settings that provide more stability. Also, it might be more efficacious to address teen health in worksite-wide programmes that include both teens and adults.

\section{Authors' affiliations}

M K Hunt, R Lederman, A Stoddard*, K Girod, G Sorensen†, DanaFarber Cancer Institute, Center for Community-Based Research, Boston, Massachusetts, USA

P Fagan, National Cancer Institute, Tobacco Control Research Branch, Rockville, Maryland, USA

L Frazier, Dana-Farber Cancer Institute, Department of Pediatric Oncology, and Brigham and Women's Hospital, Channing Laboratory, Boston. Massachusetts, USA

*Also University of Massachusetts at Amherst, School of Public Health, Department of Biostatistics and Epidemiology, Amherst, Massachusetts, USA

†Also Harvard University, School of Public Health, Department of Health and Social Behavior, Boston MA

\section{REFERENCES}

1 Pierce J, Naquin M, Gilpin E, et al. Smoking initiation in the United States: a role for worksite and college smoking bans. J Ntl Cancer Inst 1991;83:1009-13.

2 US Department of Health and Human Services. Preventing tobacco use among young people. A report of the Surgeon General, 1994. Atlanta, Georgia: Public Health Service, Centers for Disease Control and Prevention, Office on Smoking and Health, 1994. (US Government Printing Office Publication No S/N 017-001-00491-0)

3 Pentz MA, Dwyer JH, MacKinnon DP, et al. A multi-community trial for primary prevention of adolescent drug abuse. JAMA 1989;261:3259-66.

4 Perry CL, Kelder SH, Murray DM, et al. Community-wide smoking prevention: Long-term outcomes of the Minnesota Heart Health Program and the Class of 1989 Study. Am J Public Health 1992;82:1210-16.

5 Botvin GJ, Baker E, Dusenbury L, et al. Preventing adolescent drug abuse through a multi-modal cognitive-behavioral approach: results of a three year study. J Consult Clin Psychol 1990;58:437-46.

6 Hansen WB, Johnson CA, Flay BR, et al. Affective and social influences approaches to the prevention of multiple substance abuse among seventh grade students: results from project SMART. Prev Med 1988;17:135-54.
7 Peterson AVJ, Kealey KA, Mann SL, et al. Hutchinson smoking prevention project: long-term randomized trial in school-based tobacco use prevention, results on smoking. J Ntl Cancer Inst 2000;92:1979-91.

8 Glynn TJ. Essential elements of school-based smoking prevention programs. J School Health 1989;59:181-8.

9 Bachman JG, Schulenberg J. Part-time work by high school seniors: Sorting out correlates and possible consequences. Institute for Social Research, University of Michigan, 1992.

10 Light A. High school employment: national longitudinal survey discussion paper. Bureau of Labor Statistics, Washington, DC: Department of Labor, 1995.

11 Steinberg LD, Cauffman E. The impact of employment on adolescent development. Ann Child Dev 1995;11:131-66.

12 Greenberger A, Steinberg LD, Vaux A. Adolescents who work: health and behavioral consequences of job stress. Developmental Psychol 1981;17:691-701.

13 Resnick MD, Bearman PS, Blum RW, et al. Protecting adolescents from harm: findings from the national longitude study on adolescent health. JAMA 1997; 278:823-32.

14 Stanton WR, Oei TP, Silva PA. Sociodemographic characteristics of adolescent smokers. Int J Addictions 1994;29:913-25.

15 Greenwald P, Cullen JW. A scientific approach to cancer control. Cancer 1984;25:236-44

16 Flay BR. Efficacy and effectiveness trials (and other phases of research) in the development of health promotion programs. Prev Med 1986;15:451-74

17 Stoddard AM, Fagan P, Sorensen G, et al. Reducing cigarette smoking among working adolescents: Results from the SMART Study. (in review).

18 Scheirer MA, Shediac MC, Cassady CE. Measuring the implementation of health promotion programs: the case of the breast and cervical cancer program in Maryland. Health Educ Res 1995;10:11-25.

19 Israel BA, Cummings KM, Dignan MB, et al. Evaluation of health education programs: Current assessment and future directions. Health Educ $Q$ 1995;22:364-89

20 McGraw SA, Stone EJ, Osganian SK, et al. Design of process evaluation within the child and adolescent trial for cardiovascular health (CATCH). Health Educ Q 1994;(suppl 2):S5-26.

21 Linnan L, Steckler A. Process evaluation for public health interventions and research: an overview. In: Steckler A, Linnan L, eds. Process evaluation for public health interventions and research. San Francisco, California: JosseyBass, 2002.

22 Sorensen G, Fagan P, Hunt MK, et al. Changing channels for tobacco control with youth: Developing an intervention for working teens. Health Educ Res (in press).

23 Best JA. Intervention perspectives on school health promotion research. Health Educ Q 1989; 16:299-306.

24 Flay BR, Ryan KB, Best JA, et al. Are social-psychological smoking prevention programs effective? The Waterloo study. J Behav Med 1985;8:37-59.

25 Fagan $\mathbf{P}$, Eisenberg $M$, Stoddard $A$, et al. Social influences, social norms, social support and smoking behavior among adolescent workers. Am J Health Promotion 2001;15:414-21.

26 Lindsey BJ. Peer education: a viewpoint and critique. J Am College Health 1997;45:187-9.

27 Mellanby AR, Rees JB, Tripp JH. Peer-led and adult-led school health education: a critical review of available comparative research. Health Educ Res 2000; 15:533-45.

28 Backett-Milburn K, Wilson S. Understanding peer education: insights from a process evaluation. Health Educ Res 2000;15:85-96

29 Perry CL. Prevention of alcohol use and abuse in adolescents: teacher- versus peer-led intervention. Crisis 1989:10:52-61.

30 Perry CL. Creating health behavior change: How to develop community-wide programs for youth. Thousand Oaks, California: Sage Publications, 1999.

31 Milburn K. A critical review of peer education with young people with special reference to sexual health. Health Educ Res 1995; 10:407-20.

32 Hunt MK, Lederman R, Stoddard A, et al. Process tracking results from the TreatWell 5-A-Day worksite study. Am J Health Promotion 2000;14:179-87.

33 Fagan P, Stoddard AM, Hunt MK, et al. The feasibility of evaluating a tobacco control intervention for working youth. Tobacco Control 2003;12(suppl IV):iv34-9.

34 Glasgow RE, McCaul KD, Fisher KJ. Participation in worksite health promotion: a critique of the source. Health Educ Q 1993;20:391-408.

35 Sloan RP, Gruman JC. Participation in workplace health promotion programs: the contribution of health and organizational factors. Health Educ $Q$ 1988;15:269-88

36 Sturdevant MS, Speak BA. Adolescent psychosocial development. J Am Dietetic Assoc 2002;102:S30-31.

37 US Department of Labor. Report on the youth labor force. Washington DC: US Department of Labor, Office of Publications and Special Studies, Bureau of Labor Statistics, 2000

38 National Research Council, I. o. M., Protecting youth at work: health safety and development of working children and adolescents in the United States. Washington DC: National Academy Press, 1998.

39 Farkas A, Gilpin E, White $M$, et al. Association between household and workplace smoking restrictions and adolescent smoking. JAMA 2000;284:717. 